\title{
Un punto de inflexión en la historia del anarquismo: El congreso revolucionario de Londres de 1881
}

\author{
Juan AviLÉs \\ Universidad Nacional de Educación a Distancia \\ javiles@geo.uned.es
}

Recibido: 20/12/2011

Aceptado: 20/06/2012

\section{RESUMEN}

El congreso revolucionario celebrado en Londres en 1881, con asistencia de algunos de los líderes más destacados del anarquismo internacional, como Kropotkin y Malatesta, representó un intento fallido de recrear la Internacional antiautoritaria, desaparecida tras el congreso de Verviers de 1877, y mostró con ello la orientación contraria a las grandes organizaciones que predominaba en el movimiento anarquista. El congreso lanzó un llamamiento a la propaganda por el hecho y al uso revolucionario de los explosivos, que tuvo eco en atentados realizados en diversos países en años sucesivos. En cambio, el proyecto de Kropotkin de combinar las organizaciones obreras amplias con los pequeños grupos clandestinos orientados a la acción violenta no logró ponerse en práctica.

Palabras clave: Anarquismo, Asociación Internacional de Trabajadores, propaganda por el hecho, Kropotkin, Malatesta.

\section{A Turning Point in the History of Anarchism: The London Revolutionary Congress of 1881}

\begin{abstract}
The revolutionary congress that took place in London in 1881 with the presence of some of the more important leaders of the international anarchist movement, such as Kropotkin and Malatesta, was a failed effort to recreate the antiauthoritarian International that has disappeared after the 1877 Verviers congress and showed therefore the attitude against great organizations which by then dominated in the anarchist movement. The congress launched an appeal to propaganda by deed and to the revolutionary use of explosives, which was echoed in attacks perpetrated in various countries in the following years. On the other hand Kropotkin's project of combining the broad workers organizations with the small clandestine groups oriented to violent action was not implemented.
\end{abstract}

Key words: Anarchism, International Workingmen Association, propaganda by deed, Kropotkin, Malatesta.

Sumario: Introducción. 1. Los preparativos del congreso. 2. Kropotkin, Malatesta y Cafiero. 3. El problema de la organización. 4. Ciencias químicas y revolución. 5. El movimiento anarquista en los años ochenta. 6. Bibliografía. 
Abreviaturas: AN: Archives Nationales, París. APP: Archive de la Préfecture de Police, París. ASDMAE: Archivio Storico Diplomatico del Ministero degli Affari Esteri, Roma. IISH: International Institute of Social History, Ámsterdam. NA: National Archives, Kew, Londres.

\section{Introducción}

El anarquismo se estructuró como movimiento internacional tras su ruptura con el sector marxista de la Asociación Internacional de Trabajadores, que se produjo en septiembre de 1872, cuando el congreso de la Haya expulsó de la Internacional a Mijail Bakunin y éste y sus seguidores celebraron un congreso rival en la localidad suiza de Saint-Imier. Este congreso proclamó el principio anarquista de que "la destrucción de todo poder político" era "el primer deber del proletariado" y acordó el llamado pacto de Saint-Imier, que serviría como base de unión a todas las federaciones de la Internacional contrarias al "autoritarismo". La nueva Internacional antiautoritaria no tardó sin embargo en declinar y en septiembre de 1877 celebró su último congreso en la localidad suiza de Verviers.

Desapareció pues la Internacional y desaparecieron las amplias federaciones de orientación anarquista, pero persistieron los grupos clandestinos, que Bakunin siempre había considerado indispensables para el triunfo de la revolución. Bakunin había fundado la Alianza de la Democracia Socialista, que tuvo bastante arraigo en España y cuya existencia fue denunciada por los marxistas en el congreso de La Haya, y más tarde, al tiempo que se celebraba el congreso de Saint-Imier, hubo en aquella misma localidad una reunión privada en la que Bakunin y algunos de sus íntimos, incluidos los italianos Giuseppe Fanelli, Errico Malatesta, Carlo Cafiero y Andrea Costa, el suizo Schwitzguebel y los españoles Rafael Farga Pellicer, Carlos Alerini, Tomás González Morago y Nicolás Alonso Marselau, aprobaron los estatutos de una nueva organización secreta. ${ }^{1}$

Desde el inicio hubo por tanto en el anarquismo un doble proyecto de organización, que incluía por un lado a organizaciones de masas que actuaban a la luz pública, como la Asociación Internacional de Trabajadores, y por otro a pequeños grupos clandestinos. A ello se sumó la rápida difusión, a finales de los años setenta, de la creencia en que ciertos atentados podían servir como el mejor instrumento de propaganda revolucionaria, pues los hechos tendrían más eco que las palabras, con lo que la expresión "propaganda por el hecho" se convirtió en un eufemismo para referirse a los atentados. ${ }^{2}$ En diciembre de 1880, el periódico anarquista Le Révolté, fundado en Ginebra por el ruso Piotr Kropotkin, publicó un famoso artículo, atribuido a Carlo Cafiero, que llamaba a "la revuelta permanente mediante la palabra, el escrito, el puñal, el fusil y la dinamita". ${ }^{3}$

1 GUILLAUME, James: L'Internationale, documents et souvenirs, 1864-1878, vol. III, p. 1.

2 FLEMING, Marie: «Propaganda by the deed: terrorism and anarchist theory in late nineteenth-century Europe», en Y. ALEXANDER y K.A. MYERS (eds.): Terrorism in Europe, Londres, Croom Helm, 1982. BACH JENSEN, Richard: "Daggers, rifles and dynamite: anarchist terrorism in nineteenth century Europe", Terrorism and Political Violence, 16, 2004. AVILÉS, Juan: "El terrorismo anarquista como propaganda por el hecho: de la formulación teórica a los atentados de París, 1877-1894”, Historia y Política, 21, 2009.

3 Le Révolté, Ginebra, 25-12-1880. 
La propaganda por el hecho parecía ofrecer la solución al dilema de unos revolucionarios que se negaban a participar en política y no lograban impulsar hacia la revolución a las masas trabajadoras. Algunos anarquistas llegaron incluso a concluir que, si la estrategia revolucionaria se había de basar en los atentados, no eran necesarias las grandes organizaciones, porque para preparar acciones violentas bastaba con pequeños grupos clandestinos. Sin embargo, algunos líderes del movimiento, como Kropotkin y Malatesta, seguían creyendo que junto a los grupos secretos eran necesarias amplias organizaciones en las que los trabajadores se agruparan para organizar huelgas, que podrían transformarse en motines por efecto de las medidas represivas del Estado. Con ese propósito se intentó reconstruir la Internacional en un congreso celebrado en Londres en 1881, al que acudieron delegados de diversos lugares de Europa y América, en su mayoría anarquistas, o mejor dicho socialistas revolucionarios, para emplear el término con el que ellos mismos se solían denominar por entonces.

Aquel congreso no tuvo continuidad, pero marcó la orientación que dominaría en el anarquismo internacional durante dos décadas, hasta el resurgimiento de las corrientes anarcosindicalistas. Su llamamiento a la propaganda por el hecho se menciona en casi todas las historias generales del anarquismo, pero el propio congreso ha sido objeto de escasa investigación monográfica. La aportación principal se halla en un libro que Max Nettlau, pionero de la historiografía anarquista, publicó en alemán en 1931 y que nunca ha sido traducido, por lo que su difusión no ha sido muy grande. ${ }^{4}$ Sin embargo, no sólo son hoy accesibles las valiosas fuentes recopiladas por el propio Nettlau, que se conservan en el Instituto Internacional de Historia Social de Ámsterdam, sino que éstas pueden complementarse con informes policiales italianos y sobre todo franceses. Este artículo se propone utilizar todas estas fuentes para profundizar en el origen, desarrollo y significado de aquel congreso, que tan importante resulta para comprender la historia del movimiento anarquista internacional.

\section{Los preparativos del congreso}

Según los informes de la policía francesa, el proyecto original del congreso surgió en una reunión de los socialistas revolucionarios belgas celebrada en Bruselas el 19 de septiembre de 1880 y respondió al intento de contraponerlo al que pensaban celebrar en Zurich quienes defendían la participación socialista en la vida política legal. ${ }^{5}$

De su preparación se encargaron algunos militantes residentes en Londres, una ciudad considerada entonces la más libre de Europa, entre los que destacó en un primer momento el exiliado alemán Johann Most, que había sido diputado en el Reichstag por el partido socialdemócrata y pasado varios años en prisión debido a sus actividades revolucionarias. En diciembre de 1878 se exilió en Londres, donde fundó el periódico en lengua alemana Freiheit (Libertad), que inicialmente se situó en el ala más revolucionaria del partido socialdemócrata y pronto evolucionó hacia el

\footnotetext{
4 NETTLAU, Max: Anarchisten und Sozialrevolutionäre: die historische entwicklung des anarchismus in der jahren 1880-1886, Berlin, Asy-Verlag, 1931.

5 Los informes sobre los preparativos y el desarrollo del Congreso que reunió la Prefectura de Policía de París se conservan en APP, París, Ba 30.
} 
anarquismo, después de que el propio Most fuera expulsado de su partido en agosto de $1880 .^{6}$

Los preparativos del congreso resultaron difíciles, porque algunos de los pequeños grupos que fueron convocados, que contaban con escasos recursos, encontraban demasiado costoso enviar delegados a Londres. Sin embargo, algunos periódicos anarquistas de Europa y América apoyaron muy pronto la propuesta, entre ellos la Freiheit de Most y La Révolution Sociale, editada en París por un belga que se hacía llamar Serreaux, con fondos cuya peculiar procedencia se sabría luego. Por otra parte se produjeron tensiones entre Most, que era de carácter difícil, y otros miembros del comité organizador, del que formaban parte varios extranjeros residentes en Londres, como el español S. Figueras, el italiano Orlando De Martys y el francés Gustave Brocher, que invirtiendo su apellido se hacía llamar Rehcorb. ${ }^{7}$

Finalmente la convocatoria del congreso, que habría de inaugurarse en Londres el 14 de julio, aniversario de la toma de la Bastilla, se firmó el 18 de marzo de 1881, décimo aniversario de la insurrección de la Comuna, y fue reproducida en publicaciones anarquistas como La Révolution Sociale de Serreaux y Le Révolté de Kropotkin. Le Révolté no mostró sin embargo un gran entusiasmo, pues se limitó a publicar en primera página la circular que convocaba el congreso junto con otros dos documentos: la respuesta a la misma de la Federación Regional Española de la Asociación Internacional de Trabajadores y la convocatoria a un congreso socialista "político" que iba a tener lugar en septiembre de aquel año en Zurich, pero que nunca llegó a celebrarse. La citada circular, que el bureau federal de la Unión Revolucionaria Belga había remitido a la Federación del Jura, solicitaba su adhesión a un congreso que, por iniciativa de grupos socialistas franceses, ingleses, belgas y americanos se iba a reunir en Londres el 14 de julio. La convocatoria iba dirigida a "los socialistas revolucionarios de los dos mundos" (es decir, de Europa y América) y anunciaba un solo punto en el orden del día: "reconstitución de la Asociación Internacional de Trabajadores". ${ }^{8}$

La respuesta de la Federación Regional Española resultaba muy sorprendente, pues se basaba en la ficción de que la Internacional seguía existiendo "en España, en Bélgica, en Suiza, en Alemania, en Inglaterra y en América del Norte y del Sur". No había por tanto, según los españoles, necesidad alguna de reconstituirla y, aunque no se oponían a que el congreso de Londres revisara sus estatutos, no aceptarían ningún cambio que tuviera el propósito de establecer ningún tipo de autoridad central en el seno de una organización federal cuyos fines eran la anarquía y el colectivismo. La convocatoria del congreso, añadían, debía hacerla el bureau federal de la Internacional o, si éste ya no funcionaba regularmente, las federaciones regionales, y en el mismo las votaciones deberían realizarse de acuerdo a los estatutos de la Internacional, es decir a razón de un voto por cada federación. ${ }^{9}$

Poco después de que se publicara la convocatoria, Johann Most fue detenido por haber publicado en Freiheit un artículo que exaltaba el asesinato del zar Alejandro II

\footnotetext{
6 CARLSON, Andrew R.: Anarchism in Germany: the early movement, Metuchen, N.J., Scarecrow Press, 1972, pp. 173-193.

7 APP, París, Ba 30.

8 Le Révolté, Ginebra, 18-3-1881.

9 Le Révolté, Ginebra, 18-3-1881.
} 
y en junio fue condenado a dieciséis meses de trabajos forzados. ${ }^{10} \mathrm{~A}$ la preparación del congreso se sumó en cambio Errico Malatesta, una de las grandes figuras del anarquismo europeo, que llegó a Londres a comienzos de abril. Poco después, el día 25 , los organizadores dieron a conocer un manifiesto, firmado como secretario por Rehcorb, es decir Brocher, y dirigido "a los revolucionarios del mundo entero", a los que se llamaba a olvidar de momento las pequeñas diferencias que los dividían para unirse en el terreno común de la Revolución. ${ }^{11}$ El agente o confidente de la policía francesa que informaba puntualmente a París de la marcha de los preparativos creía que había motivos para alarmarse: "los Malatesta, los Figueras, por no citar más que a estos dos revolucionarios, son hombres de acción y de acción violenta sobre todo". ${ }^{12}$

Por su parte, la comisión federal española mantenía sus posiciones y en una carta del 2 de junio, además de expresar su simpatía hacia "los mártires de la revolución social en Rusia" e indicar que la mayoría de los obreros españoles habían acogido con satisfacción "la ejecución del tirano ruso", es decir el zar Alejandro, insistía en que en el congreso cada federación regional tuviera un solo voto, en vez de concedérselo a cada uno de los delegados presentes, porque no se trataba de conocer las opiniones de "algunas personalidades más o menos revolucionarias", sino la de los socialistas revolucionarios de cada región. ${ }^{13}$ Esta posición española chocaba, sin embargo, con el creciente individualismo de los grupos anarquistas, así es que, deseoso de evitar la polémica, el comité organizador optó por enviar una circular para explicar que se trataba de que en Londres se reunieran los partidarios de una unión revolucionaria internacional, sin prejuzgar si se reconstituiría la vieja Internacional o se fundaría una nueva. ${ }^{14}$

Los organizadores del congreso estaban sometidos a vigilancia por parte de la policía de varios países. No sabemos quien era la persona que enviaba a la Prefectura de París sus informes desde Londres, firmados con una estrella de cinco puntas, pero sí conocemos el nombre de varios confidentes. Uno de ellos era nada menos que uno de los miembros del comité organizador, Orlando De Martys, a quien en premio por sus servicios con motivo del congreso, el ministerio del Interior italiano otorgó más tarde una gratificación especial de 150 liras. Para evitar sospechas, De Martys solicitó incluso que se le enviaran a su domicilio dos cartas certificadas sucesivas, que le servirían para fingir que recibía de su familia dinero para vivir. En Roma no les bastaba sin embargo con tener a este confidente y en vísperas del congreso enviaron a otro desde Marsella, un cierto Moncada. De Martys informó sin embargo que los internacionalistas sospechaban de Moncada y se disponían a someterle a vigilancia. No sabemos, por otra parte, qué crédito dar a la inquietante noticia que más tarde transmitió De Martys, según el cual Malatesta habría explicado, durante el congreso, que la muerte del rey sería la señal para el inicio de la revolución social en Italia.

0 ROCKER, Rudolf: Johann Most, 1927, pp. 193-200.

11 “Congres International de Londres: Aux révolutionnaires du monde entier”, APP, París, Ba 30.

12 APP, París, Ba 30, informe de Londres, 13-5-1881.

13 Le Rèvoltè, Ginebra, 25-6-1881. El original de esta carta se conserva en IISH, Ámsterdam, Brocher papers.

14 "Premier Bulletin du Congrès de Londres", 15-6-1881, APP, París, Ba 30. 
Por su parte, Moncada proporcionó incluso el nombre de quien había de perpetrar el regicidio. ${ }^{15}$

Incluso más notable resulta el caso de otro confidente, éste al servicio de la policía francesa, pues se trataba nada menos que de Serreaux, el director de La Révolution Sociale, la combativa publicación parisina que tanto había apoyado la celebración del congreso, y que en realidad había sido fundada en septiembre de 1880 con fondos suministrados por la propia Prefectura de Policía. El prefecto Andrieux explicó más tarde en sus memorias que la difusión de la doctrina anarquista no se podía impedir con prohibiciones y que proporcionar a los anarquistas un periódico era la mejor manera de estar al tanto de lo que tramaban. Admitió incluso que les había permitido que prepararan un atentado contra una estatua de Thiers, recién inaugurada en París. Lo cierto es que los anarquistas parisinos no habían sospechado nada cuando Égide Spilleux, alias Serreaux, alias Genlis, de nacionalidad belga, se presentó en París, recomendado por un compañero residente en Bruselas, y se mostró dispuesto a financiar un periódico anarquista con los fondos que le suministraría una amiga inglesa. ${ }^{16}$ Según contó años después Gustave Brocher, fue él mismo quien, a instancias de Malatesta, que algo sospechaba, logró desenmascarar a Serreaux, mediante el sencillo procedimiento de presentarse en la casa de la supuesta proveedora inglesa de fondos, ya que el aspecto de aquel lugar desmentía a todas luces que quien allí residía pudiera financiar nada. ${ }^{17}$

\section{Kropotkin, Malatesta y Cafiero}

En los meses previos a la celebración del Congreso, algunos miembros de la asociación secreta que Bakunin había fundado años atrás, en concreto Kropotkin, Malatesta y Cafiero, intercambiaron una correspondencia acerca de la estrategia revolucionaria a seguir, que nos es conocida gracias a las pesquisas de Max Nettlau, entre cuya documentación se conserva hoy en Ámsterdam. Puesto que Kropotkin y Malatesta fueron los más influyentes líderes del anarquismo mundial en los años posteriores a la desaparición de Bakunin, este debate privado resulta muy significativo, a pesar de la escasa operatividad de su hermandad secreta.

Kropotkin, con su sólida formación militar, desconfiaba de quienes querían jugar a los soldados y preparar estados mayores revolucionarios, pero deseaba en cambio que los trabajadores se aficionaran al arte de la guerra. En una carta dirigida en febrero de 1881 a sus queridos "Charles" (Carlo Cafiero) y "Henri" (Errico Malatesta), se lamentaba de que durante la Comuna de París los revolucionarios se hubieran creído estrategas militares, mientras que olvidaban las medidas necesarias para que todos, hombres, mujeres y chiquillos se apasionaran por la revolución, pues sólo se podía hacer frente a los ejércitos regulares si se contaba con la gran masa del pueblo. ${ }^{18}$ Él

15 ASDMAE, Roma, Polizia Internazionale, B 5 y B 6.

16 MAITRON, Jean: Le mouvement anarchiste en France, París, François Maspero, 1975, vol. I, pp.141142.

17 ROCKER: Johann Most..., pp. 203-205.

18 IISH, Ámsterdam, Nettlau Papers, 3073, microfilm 1169, Kropotkin, 15-2-1881. 
era partidario de prepararse para una insurrección, pero desconfiaba en cambio de una campaña de atentados como la impulsada por sus compatriotas del grupo revolucionario Narodnaia Volia y por ello discutió con Cafiero, refugiado como él en Suiza:

Él (Cafiero) me hablaba de la acción en Italia y yo trataba de hacerle ver que si el partido socialista se volcaba exclusivamente en matar gendarmes y hacer la guerra al gobierno, la próxima revolución será de nuevo una masacre poco útil para el pueblo, mientras que tengo la firme convicción de que si un núcleo de hombres resueltos y de acción (siempre que existan los medios necesarios) se mantiene firme en la preparación de la lucha económica, la próxima revolución estará acompañada de actos de revolución social, de abolición de la propiedad individual. ${ }^{19}$

La discusión entre Kropotkin y Cafiero, que adquirió un tono muy violento, respondía a un desacuerdo de fondo. Kropotkin consideraba insuficiente una estrategia puramente terrorista encaminada a la lucha política contra el gobierno y que ignorara en cambio la revolución social. En su opinión los narodniki habían olvidado la enseñanza de Bakunin, quien les habría dicho que no era suficiente con matar al zar, pues había que matar también a los propietarios y preparar la sublevación campesina. Por su parte Cafiero, que no creía posible una conspiración clásica por falta de medios, confiaba en la acción de pequeños grupos, supuestamente más difíciles de detectar por la policía. Era necesario, argumentaba, dispersarse para resultar "impalpables e impenetrables". ${ }^{20}$

Kropotkin tampoco tenía confianza en el comité que estaba preparando el congreso de Londres. Le resultaba absurdo que Rehcorb no se atreviera siquiera a dar su verdadero nombre, y tampoco tenía buena opinión del grupo belga que había propuesto el congreso y había tenido la malhadada idea de celebrarlo en Londres, tan lejos de su lugar de residencia en Suiza. ${ }^{21}$ Consideraba a esos belgas "blanquistas", es decir seguidores de Auguste Blanqui, el veterano conspirador socialista francés que tras haber pasado buena parte de su vida en prisión había fallecido en enero de 1881, cuya estrategia se basaba en la conquista violenta del poder y el establecimiento de una dictadura revolucionaria. En la pluma de un libertario como Kropotkin, la acusación de "blanquismo" implicaba el temor a que se pretendiera imponer al partido revolucionario una organización jerárquica.

En otra carta, Kropotkin añadió que desconfiaba de la influencia oculta de Marx y también de Serreaux y temía que en el congreso Malatesta, Cafiero y los delegados de España y del Jura, es decir aquellos en quienes él confiaba, se encontraran en minoría frente a quienes pretenderían crear un comité director institucionalizado (los blanquistas). Su visión acerca de las fuerzas con que contaba el anarquismo era pesimista, pues lo creía falto de un núcleo capaz de impulsarlo. Explicaba que la Federación del Jura había quedado aislada, que él en Ginebra se hallaba demasiado ocupado con Le Révolté y con la necesidad de trabajar para ganarse la vida, que Cafiero se hallaba en peligro de ser expulsado de Lugano (de hecho lo fue unos meses después) y que

19 IISH, Ámsterdam, Nettlau Papers, 3073, microfilm 1169, Kropotkin, 4-5-1881.

20 IISH, Ámsterdam, Nettlau Papers, 3072, microfilm 1169, Cafiero, 26-6-1881.

21 IISH, Ámsterdam, Nettlau Papers, 3073, microfilm 1169, Kropotkin, 22-6-1881. 
Malatesta se había visto forzado (tras siete meses de cárcel en París) a refugiarse en Londres, donde se hallaba en un medio poco favorable. En su opinión, la revolución sólo estaba próxima en Irlanda, donde los anarquistas carecían por completo de influencia, y en Rusia, donde el movimiento revolucionario, compuesto por una extrema diversidad de grupos e individuos, nunca aceptaría una influencia internacional. Una coordinación revolucionaria internacional como la que se pretendía lograr en el congreso de Londres, podría en cambio resultar eficaz respecto a Italia, Francia, España y Alemania, pero para ello sería necesario crear no una, sino dos organizaciones, una abierta y amplia y otra secreta y poco numerosa. Ésta debía orientarse a la acción, mientras que aquella debería ser una organización internacional de resistencia, que no se ocuparía de política, sino sólo de huelgas:

Yo no veo otro campo de actuación para todos aquellos que no pueden incorporarse a grupos secretos que la de agruparse bajo las banderas de la Internacional huelguista. Es sólo en ésta donde se podrán agrupar las fuerzas obreras, la masa. No veo por otra parte ningún inconveniente en ello. La huelga no es ya una guerra de brazos cruzados. El gobierno se encarga continuamente de transformarla en motín. Esto por un lado. Por otro lado, los grupos secretos se encargarían de organizar la conspiración obrera: hacer saltar una fábrica, 'tranquilizar' a un patrón o a un capataz, etc. etc. lo que reemplazaría con ventaja la propaganda de los congresos. ${ }^{22}$

Vemos pues que Kropotkin concebía la acción violenta, ejercida por grupos clandestinos como íntimamente ligada a unas luchas obreras radicalizadas por los efectos de la represión, algo muy distinto del terrorismo político impulsado por Narodnaia Volia. La organización de resistencia amplia proporcionaría fuerzas, dinero y un medio propicio a los grupos secretos. Estos últimos deberían contar además con un vínculo internacional, para lo cual habría que recurrir a los "hermanos internacionales", es decir a la sociedad secreta creada años antes por Bakunin. El núcleo de esta subsistía, según Kropotkin, integrado por Malatesta, Cafiero, Adhémar (de la Federación del Jura), Louis (Pindy?), él mismo y dos más a quienes podemos identificar como españoles: Rodríguez (pseudónimo de José García Viñas) y Mor. (posiblemente Tomás González Morago). Sólo habría que reforzarlo con una docena de jóvenes "activos, buenos conspiradores y hombres de acción", pero de esto no se podría hablar en un congreso, así es que en Londres lo único que habría que hacer sería evitar que se constituyera un ineficaz comité revolucionario central.

Por su parte, Malatesta trató de tranquilizar a Kropotkin respecto a la comisión organizadora del congreso, que en su opinión, aunque no se mostraba muy activa, al menos no pretendía asumir la dirección del movimiento, ni tampoco se hallaba mediatizada por Marx, como sospechaba el ruso. A la mayoría de sus miembros los consideraba una nulidad, pero tenía buena opinión de Gustave Brocher, de quien ofrecía en su carta un retrato pintoresco:

Brocher es un filólogo, muy sabio parece ser, que tiene la pasión de coleccionar libros, periódicos, grabados, etc., que hace música, habla no sé cuantas lenguas y se

22 IISH, Ámsterdam, Nettlau Papers, 3073, microfilm 1169, Kropotkin, sin fecha. 
siente muy apenado porque no tiene tiempo para aprender árabe y persa. (...) Todo sumado es, en mi opinión, muy buen muchacho, un poco artista, algo tímido, siempre dispuesto, creo, a dejar una barricada para ir en busca de un libro raro, con la misma buena fe con la que come algunas veces pan seco para comprarse un grabado; y quizá dispuesto también a perderse un libro raro para acudir a una barricada. (...) A veces ve a Marx, pero no creo que le estime; por cuanto sé, no ha dicho nunca abiertamente que sea anarquista, pero (...) se declara revolucionario y enemigo de los medios legales. ${ }^{23}$

Malatesta pensaba que con el apoyo de los delegados españoles, suizos e italianos, de la mayor parte de los belgas y franceses y de casi todos los residentes en Londres, tendrían mayoría en el congreso frente a los blanquistas de Bélgica y de París. Respecto a Serreaux, Malatesta no sabía de sus contactos con la policía parisina, pero no se fiaba de él: "Más que a los blanquistas, con los que hay manera de entenderse en el terreno práctico, temo las intrigas de Serreaux". Pretendía que del congreso saliera algo útil y se inclinaba por la constitución, no de dos, sino de tres organizaciones:

Pierre (Kropotkin) nos propone la reconstitución de la Internacional huelguista y dentro de la Internacional una organización secreta, en una palabra, la Alianza. Yo creo que a estas dos organizaciones hay que añadirle una tercera, la Liga revolucionaria. Hay que crearla porque resultara útil y además porque si no lo hacemos se creará sin nosotros y contra nosotros. La Liga revolucionaria belga que ha tomado la iniciativa de este congreso con el propósito de transformarse en organización internacional no querrá renunciar a ello; y está bien, porque en mi opinión, una liga formada por todos aquellos que, aun teniendo programas diferentes, concuerdan en la necesidad de venir a las manos lo más pronto posible, puede estar hoy llamada a prestar grandes servicios. $^{24}$

Kropotkin y Malatesta coincidían pues con el modelo que Bakunin había pretendido imponer diez años antes: una organización amplia de trabajadores, pública en la medida de lo posible, dedicada a la lucha contra el capital y a las huelgas, pero ajena a toda acción política y sobre todo electoral, y en su seno una organización revolucionaria secreta. La primera podría consistir en una renovada Asociación Internacional de Trabajadores que siguiera el patrón, matizaba Malatesta, de la "Internacional anarquista de 1873", es decir la que se constituyó tras la ruptura con los marxistas, basada en la completa autonomía de los grupos que la componían. La segunda sería la heredera de la antigua sociedad secreta de Bakunin, a la que Malatesta se refería como la Alianza. La novedad que proponía el italiano era esa liga revolucionaria en la que, junto a los anarquistas, tendrían cabida todos aquellos que estuvieran de acuerdo en no utilizar más medios que los revolucionarios, como era el caso de los blanquistas. Pensaba por tanto que el congreso podría servir tanto para reconstituir la Internacional como para crear esa liga, que por otra parte habría de tener una estructura muy laxa, carente de un órgano central. En cuanto a la Alianza secreta de los anarquistas, no debía constituirse en el congreso, sino al margen de él. Malatesta era consciente que en el congreso habría confidentes de la policía y por tanto sostenía que en él sólo

23 IISH, Ámsterdam, Nettlau Papers, 3075, microfilm 1169, Malatesta, sin fecha.

24 IISH, Ámsterdam, Nettlau Papers, 3075, microfilm 1169, Malatesta, sin fecha. 
se deberían trazar las líneas generales de actuación del partido revolucionario, que se harían públicas, mientras que los acuerdos concretos se deberían tomar en reuniones íntimas entre delegados de confianza. No creía necesario que se ocultara a los otros revolucionarios la existencia de una Alianza anarquista secreta, pero sí pensaba que se debería mantener oculta la identidad de sus miembros.

Cafiero, en cambio, sólo confiaba en la acción de pequeños grupos aislados y esta diferencia, que hemos visto a través de su correspondencia íntima, salió también a la luz en la prensa anarquista. A comienzos de julio Il Grido del Popolo de Nápoles publicó sendas cartas de Malatesta y de Cafiero acerca del inminente congreso de Londres, en las que el primero preconizaba el entendimiento entre todos quienes rechazaban la participación política y se aprestaban a la insurrección, al margen de cuales fueran sus ulteriores planes, mientras que el segundo defendía la acción de grupos aislados:

En este congreso los legalistas y los parlamentaristas brillarán por su ausencia y todos los reunidos estarán perfectamente de acuerdo en la necesidad de los medios violentos. Por tanto todo el orden del día se reducirá a la siguiente cuestión: ¿cómo organizaremos la violencia?

A este pregunta se propondrán dos respuestas, una de la escuela clásica, otra de la escuela moderna; la primera propugnará el orden compacto de la falange o de la cohorte, la segunda en cambio sostendrá el orden disperso de los manípulos; los unos querrán una gran concentración de fuerzas, los otros una inmensa diseminación de fuerzas (...). En otras palabras, todo el campo se dividirá entre los revolucionarios, que en la práctica son autoritarios, y los anarquistas (...)

No más centros, por tanto, no más oficinas de correspondencia o de estadística, no más planos generales precedentemente elaborados, Que cada uno trate de formar en su propia localidad un grupo alrededor de sí, constituyendo un manipulo que se empeñe sin más en la acción. Diez hombres, seis hombres, pueden realizar en una ciudad actos que encontrarán eco en todo el mundo. ${ }^{25}$

Es obvio que el único acto con el que un puñado de hombres podría lograr eco en todo el mundo era un atentado. La oposición de Cafiero a las grandes organizaciones revolucionarias, que en parte provenía de sus dudas respecto a su efectividad pero también respondía a la lógica intrínseca del anarquismo, conducía así hacia una táctica basada en los atentados aislados, un camino que muchos anarquistas seguirían en las décadas siguientes. Sin embargo la objeción de Kropotkin tenía serio fundamento, pues una violencia ejercida por grupos aislados respecto a la lucha de las masas podría llenar muchos titulares de prensa, como en efecto ocurrió, pero nunca supondría una vía hacia la revolución social. El ruso, por su parte, esperaba que en el congreso de Londres se reconstituyera la organización revolucionaria internacional de masas. En vísperas del congreso, Le Revolté expresó su deseo de que los socialistas revolucionarios de todos los matices entraran en bloque en la Asociación Internacional de

25 C. Cafiero, Il Grido del Popolo, Nápoles, 4-7-1881, reproducido en DADÁ, Adriana: L'anarchismo in Italia fra movimento e partito: storia e documenti dell'anarchismo italiano, Florencia, Teti, 1984, pp. $190-194$. 
Trabajadores, a la que luego se unirían las grandes masas para dar el golpe mortal a la burguesía y a los gobiernos. ${ }^{26}$

El propio Cafiero, que empezaba a manifestar indicios de trastornos psíquicos, no participó en el congreso de Londres y en 1882 regresó a Italia, donde para sorpresa general se declaró favorable a la participación electoral, pero a partir de entonces su salud mental se deterioró con rapidez.

\section{El problema de la organización}

La llegada de los delegados a Londres fue registrada por los informadores de la policía francesa, que ofrecieron de algunos de ellos una descripción física que facilitara su identificación. La de Kropotkin, no encajaba con la de un príncipe ruso, sino con la de quien, como él mismo se quejaba en sus cartas, se ganaba la vida con dificultad:

Es un hombre de más de cuarenta años (en realidad los cumplió al año siguiente), muy alto, pero no demasiado corpulento, vestido de manera algo mugrienta, como un mercader judío; con un sombrero deformado, sucio, con una barba larga y abundante, pero la cabeza casi calva. Lleva gafas y tiene tres o cuatro dientes de arriba ennegrecidos y como rotos. ${ }^{27}$

El delegado de las federaciones de España, al que llamaban Manuel, tenía mejor aspecto. Era bajo y fornido, lucía un fino bigote negro y vestía muy decentemente, con un traje de obrero con pantalón y chaleco claros y chaqueta negra de fantasía, camisa de color y un pequeño sombrero redondo. Hablaba muy bien el francés, dado que había nacido en Lyon, pero residía en Barcelona. Al margen de estos datos, el informante no sabía nada más, ni siquiera su apellido. Probablemente se tratara de Emmanuel Fournier, quien había jugado un papel destacado en los primeros años de la Internacional en España, como miembro de la sección de lengua francesa de Barcelona. ${ }^{28}$

Según Le Revolté, en el congreso participaron cuarenta y cinco delegados, que representaban a 60 federaciones y 59 grupos o secciones. Además del delegado del comité organizador, había quince delegados de organizaciones de Inglaterra (varias de ellas de inmigrantes), once de Francia, cuatro de Estados Unidos, tres de Bélgica, dos de España, de Italia, de Alemania y de Suiza, y uno de los Países Bajos, de Serbia y de México. Por evidentes motivos de prudencia, Le Révolté no dio los nombres de aquellos delegados, pero casi en su totalidad han sido identificados por Max Nettlau. ${ }^{29}$ Entre ellos cabe mencionar a Kropotkin y a Malatesta; al ya citado Gustave Brocher, que participó como delegado de la comunidad icariana de Iowa, una comuna rural fundada en 1853 por discípulos del socialista francés Étienne Cabet; a los confidentes policiales Serreaux, De Martys y Moncada; a Francesco Saverio Merlino, una figura

26 Le Révolté, Ginebra, 9-7-1881.

27 APP, París, Ba 30, informe de Londres, 13-7-1881.

28 Referencias a E. Fournier en TERMES, Josep: Anarquismo y sindicalismo en España: la Primera Internacional, 1864-1881, Barcelona, Ariel, 1972, pp. 153, 178, 245 y 460.

29 NETTLAU: Anarchisten..., pp. 187-201. 
importante en la historia del anarquismo italiano; al doctor Edward Nathan-Ganz, de Boston, que llegó como delegado de los trabajadores de México y destacó en el congreso por su defensa del uso de los explosivos; ${ }^{30}$ a la francesa Louise Michel, una ardiente propagandista que había participado en la Comuna y había sido deportada a Nueva Caledonia, de donde regresó en 1879; a Emmanuel Chauvière, delegado del grupo belga que había promovido el congreso; y a la francesa Victorine Rouchy, que había sido condenada a muerte por su participación en la Comuna, logró escapar al extranjero, retornó a Francia tras la amnistía y se incorporó al grupo La Révolution Sociale del confidente Serreaux. Más tarde Gustave Brocher y Victorine Rouchy contraerían matrimonio.

Existe cierta duda acerca de la identidad de los delegados españoles. Según $L e$ Révolté, hubo un delegado de la Federación Regional Española de la Internacional y otro de una de las uniones de oficio que la integraban, la Unión de Constructores de Edificios. En la documentación del congreso conservada en Ámsterdam, se encuentra el mandato que 26 secciones de esta Unión, todas ellas de la provincia de Barcelona, otorgaron a su delegado, sin especificar su nombre, así como varios documentos de la Federación Regional Española, que afirmaba contar con 49 federaciones locales agrupadas en siete federaciones comarcales. ${ }^{31}$ Un informe recibido por la policía de París mencionó a un cierto Manuel como delegado español, mientras que otro indicó que uno de los integrantes de la comisión encargada de verificar los mandatos era un cierto Fournier, por lo que es probable que se tratara del ya citado Emmanuel Fournier, un francés afincado en Barcelona. ${ }^{32}$ Sin embargo, Max Nettlau, que era un investigador muy minucioso, no mencionaba a Fournier entre los delegados, identificaba a S. Figueras, un mecánico residente en Londres cuya participación en los preparativos del congreso ya hemos mencionado, como el delegado de la Federación Regional Española y se preguntaba si lo habría sido también de la Unión de Constructores de Edificios. ${ }^{33}$ Lo más probable es que hubiera dos delegados españoles, Figueras, delegado de la propia Federación, y Fournier, delegado de las secciones de la construcción de Barcelona.

Las sesiones se prolongaron del 14 al 19 de julio y un resumen de los debates fue más tarde publicado en Le Révolté, sin mencionar los nombres de quienes intervinieron, a quienes se puede identificar mediante la lista establecida por Nettlau. El primer debate se suscitó cuando el delegado de la Federación Española, es decir Figueras, planteó la cuestión de cómo se votaría, proponiendo que se hiciera por federaciones, aunque al final se acordó por unanimidad que se votaría por delegados respecto a las cuestiones de organización del propio congreso, mientras que respecto a las demás cuestiones el congreso se limitaría a constatar qué organizaciones representadas en el mismo las aceptaban. En realidad, el Congreso no pretendió tomar decisiones vinculantes, sino que acordó limitarse e indicar "las líneas generales" de lo que consideraba debía ser la organización socialista revolucionaria, mientras que dejó "a la

\footnotetext{
30 AVRICH, Paul: The Haymarket tragedy, Princeton University Press, 1984, pp. 57-58.

31 IISH, Ámsterdam, Brocher papers.

32 APP, París, Ba 30, informe de Londres, 15-7-1881.

33 NETTLAU: Anarchisten..., pp. 8 y 14.
} 
iniciativa de los grupos" el tema de "las organizaciones secretas y de otro tipo" que serían útiles para el triunfo de la revolución. ${ }^{34}$

El delegado número 25, es decir Malatesta, que representaba a diversos grupos italianos, propuso en la sesión del 15 de julio que la Asociación Internacional de Trabajadores se reconstruyera con una orientación revolucionaria de lucha contra los gobiernos, para lo cual era necesaria una doble estructura, por un lado un órgano destinado a difundir propaganda entre las masas e impulsarlas a la revuelta, y por otro unos grupos de acción, organizados y federados en secreto para la acción violenta. El delegado de la Federación Española, es decir Figueras, destacó la importancia de las uniones de oficio como base de la organización, porque sólo así se podía atraer a la gran masa de los trabajadores y preparar las fuerzas de la revolución, como se hacía en España. El delegado 26, es decir el italiano Merlino, se mostró por su parte contrario a que ese tipo de organización, que hoy denominaríamos sindical, se adoptara en otros países, pues no creía oportuno convertir a la organización socialista revolucionaria en una organización puramente obrera, ya que la cuestión social no lo era, y además en Italia existían numerosos grupos que no estaban integrados por trabajadores, sino por estudiantes.

Tampoco era Merlino partidario de que se explicitara en el programa de la nueva organización el objetivo del comunismo anárquico, pues sólo en plena revolución se podrían concretar los objetivos finales. En cambio, el delegado de Le Révolté, es decir Kropotkin, consideraba necesario establecer de antemano el programa revolucionario, para que en la próxima revolución los trabajadores mismos tomaran desde el comienzo posesión de toda la riqueza social y la pusieran en común, lo que requeriría la existencia de una poderosa organización obrera. A lo cual el delegado de los trabajadores de la construcción de Barcelona, es decir Fournier, añadió que deberían ser las uniones de oficio las que en la próxima revolución se apoderaran de los instrumentos de trabajo.

Tras ello, Malatesta intervino de nuevo con una actitud muy abierta. Sostuvo que a la nueva organización internacional se podrían unir todas las entidades que aprobaran sus principios, sin necesidad de modificar su propia estructura. Por otra parte, se declaró partidario del comunismo anarquista, pero argumentó que la Internacional debía dar cabida a todos los que pretendían derribar el orden político y social existente, al margen de cual fuera su proyecto de sociedad futura. En cuanto al nombre de la nueva organización, la mayoría de los delegados se mostraron favorables a mantener el de Asociación Internacional de Trabajadores, con el voto en contra de Merlino, quien habría preferido denominarla Asociación Internacional Socialista-Revolucionaria..$^{35}$

En la sesión del 17 de julio hubo un intenso debate acerca de la propuesta de la comisión encargada de estudiar la estructura de la nueva Internacional, que era favorable a que ésta se dotara, como su predecesora, de un bureau de correspondencia, cuya misión sería facilitar la conexión ente los diferentes grupos adheridos. A ello se opusieron varios delegados franceses, que veían en ello el peligro de que surgiera un poder autoritario y evocaron el precedente del Consejo General de Londres, que

34 Le Révolté, Ginebra, 23-7-1881.

35 Le Révolté, Ginebra, 6-8-1881. 
había impuesto su dominio sobre la primera Internacional. Pero los partidarios de la propuesta replicaron que no se trataba de crear ningún tipo de autoridad, sino de un bureau que se ocupara simplemente de facilitar la correspondencia, y Kropotkin subrayó la imposibilidad práctica de que unos centenares de grupos pudieran estar en comunicación directa entre ellos, así es que, si se descartaba el bureau, esa tarea recaería sobre los periódicos, que no estaban en condiciones de ejercerla adecuadamente, como él mismo había podido comprobar por su experiencia en Le Révolté. Al final la mayoría de los delegados se mostraron favorables a la creación del bureau de correspondencia internacional. ${ }^{36}$

El 18 de julio el congreso eligió a los tres miembros de dicho bureau, que tendría su sede en el club socialdemócrata de trabajadores de Rose Street, en Londres. Por obvios motivos de prudencia, Le Révolté no publicó sus nombres, pero la policía francesa tuvo inmediato conocimiento de ellos: se trataba de Errico Malatesta, del alemán Sebastian Trunck, del club de Rose Street y de Nikolai Chaikovski, del Club Eslavo de Londres. ${ }^{37}$

A continuación se debatió el procedimiento de admisión y la mayoría de los delegados admitió la propuesta que en nombre de la comisión hizo Malatesta, según la cual todo grupo tenía derecho a ingresar en la Internacional, si admitía sus principios, y también lo tenía cualquier individuo. Kropotkin hubiera querido también que se acordara la celebración periódica de congresos, pero su propuesta encontró la oposición de algunos delegados, por lo que se acordó que la fecha y lugar de celebración del próximo congreso se dejaría a la iniciativa de las organizaciones integrantes de la Internacional. Respecto a las actas del congreso, se acordó que no se elaborarían de forma oficial, sino que se encomendó a la prensa revolucionaria la tarea de divulgar lo tratado. ${ }^{38}$

El congreso aceptó mantener la declaración de principios de la primitiva Asociación Internacional de Trabajadores, pero surgió un problema respecto a la afirmación de aquella según la cual su conducta se basaría en la justicia, la verdad y la moral. La mayoría de los delegados querían que se suprimiera la palabra moral pero, para mantener integra la declaración primitiva, se acordó limitarse a matizar su significado mediante el añadido de que, puesto que la sociedad existente se basaba en la inmoralidad, sería la abolición de esa sociedad por todos los medios la que conduciría a la moralidad. Lo cual se parecía mucho a proclamar que la moralidad de los fines revolucionarios justificaría cualquier medio que se empleara.

Respecto al modelo de organización, los "representantes de los socialistas revolucionarios de los dos mundos" reunidos en Londres, "todos ellos partidarios de la destrucción integral de las instituciones por la fuerza" y convencidos de que había llegado la hora de añadir a la propaganda oral y escrita, cuya ineficacia creían demostrada, "la propaganda por el hecho y la acción insurreccional", propusieron a los grupos que se adhirieran a la Internacional las resoluciones siguientes:

36 Le Révolté, Ginebra, 20-8-1881.

37 APP, París, Ba 30, informe de Londres, 23-7-1881.

38 Le Révolté, Ginebra, 20-8-1881. 
La Asociación Internacional de Trabajadores se declara adversaria de la política parlamentaria. (...)

Cada grupo adherido tendrá el derecho de corresponder directamente con los otros grupos que podrán darle su dirección.

No obstante, para facilitar las relaciones, se establecerá un bureau internacional de información. (...)

Un congreso internacional se reunirá según las necesidades de los grupos y federaciones adheridas. ${ }^{39}$

\section{Ciencias químicas y revolución}

En su última sesión, celebrada el 19 de julio, el congreso decidió la creación de una prensa clandestina en los distintos países y debatió extensamente sobre la aplicación de las ciencias químicas y eléctricas, eufemismo bajo el que se ocultaba el interés por la fabricación de artefactos explosivos. El tema fue planteado por el delegado de la Federación mexicana, el estadounidense Edward Nathan-Ganz y obtuvo un apoyo mayoritario, aunque Kropotkin quiso matizar que el ejemplo de los revolucionarios rusos demostraba que el dominio de la química y la electricidad no se improvisaba y que los grupos no debían por tanto convertirse en escuelas de química, sino fomentar que hubiera compañeros que se formaran de verdad, trabajando por ejemplo en la industria química. Kropotkin, formado él mismo en una excelente academia de oficiales, tampoco compartía el entusiasmo de algunos delegados por la preparación militar, ya que en su opinión el triunfo no dependería de contar con oficiales preparados, sino del entusiasmo revolucionario de las masas. No está del todo claro, por otra parte, hasta que punto los delegados que insistían en la importancia de las ciencias químicas estaban pensando en preparativos para una insurrección revolucionaria o más bien en la "propaganda por el hecho", término que empleó específicamente el delegado de La Révolution Sociale, es decir Serreaux, el confidente de la policía parisina. Por otra parte, no todos los delegados compartían la convicción de Kropotkin de que no se podía aprender química mediante unas pocas instrucciones, pues un delegado alemán, Baltasar Hohn, propuso que los conocimientos químicos se divulgaran en la prensa revolucionaria. De hecho, en los siguientes años hubo periódicos anarquistas que publicaron instrucciones para la elaboración de explosivos. ${ }^{40}$

Este entusiasmo por la aplicación revolucionaria de la química es el principal motivo por el que se recuerda aquel congreso, ya que se aprobó una declaración, luego difundida en la prensa anarquista de varios países, en la que se indicaba que el avance hacia la revolución exigía la propaganda por el hecho y las ciencias químicas eran presentadas como un gran instrumento para ese peculiar tipo de propaganda:

\footnotetext{
39 Le Révolté, Ginebra, 23-7-1881. Un texto previo y casi idéntico, obtenido por los informadores de la policía francesa, se menciona en un informe policial francés: APP, París, Ba 30, Londres, 23-7-1881.

40 Le Révolté, Ginebra, 20-8-1881.
} 
Es estrictamente necesario hacer todos los esfuerzos posibles para propagar mediante actos la idea revolucionaria y el espíritu de revuelta en esa gran fracción de la masa popular que no toma todavía parte activa en el movimiento y se hace ilusiones sobre la moralidad y la eficacia de los medios legales.

Saliendo del terreno legal, en el que por lo general se ha permanecido hasta ahora, para llevar nuestra acción al terreno de la ilegalidad que constituye el único camino hacia la revolución, es necesario recurrir a los medios que estén en conformidad con este propósito. (...)

Puesto que las ciencias técnicas y químicas han rendido ya servicios a la causa revolucionaria y están llamadas a rendir todavía más en el futuro; el Congreso recomienda a las organizaciones e individuos que forman parte de la Asociación Internacional de Trabajadores que den una gran importancia al estudio y la aplicación de estas ciencias como medio de defensa y de ataque. ${ }^{41}$

\section{El movimiento anarquista en los años ochenta}

El congreso de Londres mostró la fascinación que entre los anarquistas despertaban entonces los atentados con explosivos, al tiempo que su creciente rechazo hacia todo tipo de organización. Su llamamiento a la aplicación de las ciencias químicas tuvo repercusiones en varios países, pero en cambio sus resoluciones para la reconstitución de la Internacional no se aplicaron y el bureau internacional de Londres nombrado en el congreso no tuvo actividad conocida. El propio Malatesta, su miembro más significado, dio en el verano de 1882 una orientación inesperada a su deseo de acción, pues al tener noticia de que se había iniciado una rebelión árabe en Egipto se dirigió a ese país con otros tres italianos, aunque no lograron sino ser arrestados en Alejandría por las autoridades inglesas. ${ }^{42}$ La liga revolucionaria internacional que Malatesta había imaginado nunca se hizo realidad y la hermandad secreta que le unía a Kropotkin, Cafiero y otros militantes debió desintegrarse por aquellas fechas, si es que alguna vez había tenido operatividad real.

El modelo que en vísperas del congreso había esbozado Kropotkin, el de una gran organización obrera de inspiración anarquista dedicada a la lucha económica, en el seno de la cual habrían operado los grupos secretos orientados a la acción violenta, renacería décadas más tarde en España y haría de la CNT la fuerza anarquista más poderosa de la historia. De momento, sin embargo, el movimiento anarquista entró tras el congreso de Londres en una prolongada etapa de fragmentación en pequeños grupos autónomos, que mantenían contactos entre ellos pero carecían de una coordinación efectiva. Las únicas excepciones fueron la Federación de Trabajadores de la Región Española, fundada en Barcelona 1881, y la International Working People Association, fundada en Pittsburg en 1883, que adquirieron cierta influencia entre los trabajadores del Este y el Sur de España, la primera, y de Chicago, la segunda.

La Federación de Trabajadores de la Región Española, heredera de la Federación Regional Española de la Internacional, que como hemos visto había estado represen-

41 Le Révolté, Ginebra, 23-7-1881.

42 BERTI, Giampietro: Errico Malatesta e il movimento anarchico italiano e internazionale, 1872-1932, Milano, Franco Angeli, 2003, pp. 98-99. 
tada por dos delegados en el congreso de Londres, adoptó su nueva denominación en un congreso que se celebró en Barcelona, en septiembre de 1881. Revolucionaria en sus objetivos, que se resumían en anarquía, federación y colectivismo, la nueva organización trató sin embargo de actuar a la luz pública y en la legalidad, en contra de lo acordado en el congreso de Londres. Se estructuró en federaciones locales y secciones de oficio, se dotó de una Comisión Federal y llegó a contar con casi cincuenta mil afiliados, que se concentraban sobre todo en Andalucía y Cataluña, según los datos que hizo públicos en septiembre de 1882, cuando celebró su segundo congreso en Sevilla. ${ }^{43}$

No todos los anarquistas españoles aceptaron sin embargo este modelo organizativo público y en ciertas localidades de Andalucía occidental el movimiento mantuvo la estructura clandestina que había adoptado durante los años en que su federación estuvo prohibida, es decir desde 1874 hasta 1881. Los partidarios de la lucha clandestina, que más tarde se agruparon en una organización disidente mal conocida, que se denominó Los Desheredados, acusaron a los dirigentes de la Federación de haber ignorado la resolución del congreso de Londres favorable a la propaganda por el hecho. ${ }^{44}$ En ese contexto se produjeron en los campos de Jerez los crímenes que se han atribuido, sin fundamento, a una misteriosa organización llamada la Mano Negra, y que en realidad, al menos en el caso del más notorio, el llamado crimen de la Parrilla, parecen haber sido cometidos por una organización clandestina local vinculada a la Federación de Trabajadores de la Región Española ${ }^{45}$ La Comisión Federal de ésta se disoció sin embargo de tales crímenes y del mismo concepto de propaganda por el hecho, al afirmar en un manifiesto que la propaganda a favor de la revolución social no podía hacerse ni por el robo, ni por el secuestro, ni por el asesinato. ${ }^{46}$ Pero al final, las disensiones internas, las dificultades puestas por las autoridades a la actuación legal de las sociedades obreras y el clima creado por los turbios crímenes que la opinión pública atribuyó a la Mano Negra, aunque la existencia de ésta nunca se probó en sede judicial, contribuyeron a un rápido declive de la federación, que desapareció a fines de los años ochenta.

Otro hecho sangriento, la bomba lanzada por un desconocido durante un mitin anarquista junto a la plaza de Haymarket en Chicago el 4 de mayo de 1886, que causó la muerte a siete policías, contribuyó decisivamente al hundimiento de la poderosa organización obrera anarquista de aquella ciudad. ${ }^{47} \mathrm{El}$ anarquismo americano se había consolidado como movimiento en el congreso de Pittsburg de octubre de 1883, en el que varios grupos que por entonces se denominaban socialistas revolucionarios se unieron para formar la International Working People Association, es decir Asociación Internacional de Trabajadores, que en realidad no fue más que una laxa federación de

\footnotetext{
43 Revista Social, Madrid, 20-10-1881 (congreso de Barcelona), 21-9-1882 (principios anarquistas) y 5-10-1882 (congreso de Sevilla).

44 La Revolución Social, $\mathrm{n}^{\mathrm{o}}$ 5, abril de 1885.

45 LIDA, Clara E.: La mano Negra: anarquismo agrario en Andalucía, Madrid, Zyx, 1973. CASTRO ALFÍN, Demetrio: Hambre en Andalucia: antecedentes y circunstancias de la Mano Negra, Ayuntamiento de Córdoba, 1986.

46 Revista Social, 22-3-1883.

47 AVRICH: The Haymarket tragedy... GREEN, James: Death in the Haymarket, Nueva York, Anchor Books, 2006.
} 
grupos autónomos y nunca llegó a celebrar un segundo congreso. Su principal bastión fue Chicago, donde el anarquismo se difundió sobre todo entre los trabajadores inmigrantes de lengua alemana. La prensa anarquista norteamericana se mostraba por entonces entusiasmada por las posibilidades revolucionarias que ofrecía un nuevo explosivo recién inventado: la dinamita. En línea con lo afirmado en el congreso de Londres acerca de las ciencias químicas, un artículo publicado en febrero de 1885 por un periódico anarquista de Chicago llegó a afirmar que, al proporcionar la dinamita "a los millones de oprimidos del mundo", la ciencia había hecho "su mejor trabajo". ${ }^{48}$

En aquellos días de la primavera de 1886 los anarquistas de Chicago participaban en un gran movimiento por la jornada de ocho horas, que había dado lugar a sangrientos enfrentamientos entre huelguistas y guardias privados. Nunca se supo quien había lanzado la fatídica bomba de Haymarket, pero cuatro militantes anarquistas de la ciudad, incluidos sus dos líderes más significados, fueron ejecutados por aquel crimen. Ello dio al anarquismo internacional sus primeros grandes héroes, los "mártires de Chicago", pero la tragedia de Haymarket condujo a un rápido declive del por un momento vigoroso movimiento anarquista de aquella gran ciudad industrial americana.

Uno de los principales propagandistas del anarquismo en los Estados Unidos era el alemán Johann Most, que había sido uno de los promotores del congreso de Londres, pero no pudo participar en él por haber sido condenado a prisión en Inglaterra. Most se estableció en Nueva York en 1882, tras ser liberado, y se convirtió allí en un gran defensor del uso revolucionario de los explosivos, que describió en un manual publicado en $1885 .{ }^{49}$ Trasladó también a Nueva York la edición de su periódico en lengua alemana Freiheit, que había comenzado a propugnar la realización de atentados ya durante su etapa londinense. En diciembre de 1880 había aparecido en sus páginas un artículo con el expresivo título de "Durch Terrorismus zur Freiheit", es decir "por el terrorismo hacia la libertad", aunque el término terrorismo, usado por los revolucionarios rusos, no arraigó entre los anarquistas occidentales, que preferían referirse a la propaganda por el hecho. Esta última expresión, en alemán "Die Propaganda durch die That", apareció en el título de varios artículos publicados por Freiheit a partir de 1881, mientras que otros tenían un enfoque más práctico y reflejaban su fascinación por la química en títulos como "Die Chemie und die Revolution", "Dynamit" o "Das Nytroglyzerin", que no requieren traducción. ${ }^{50}$ En el otoño de 1882 algunos de estos artículos llamaron la atención de Scotland Yard, que en uno de sus informes destacó la gravedad de un artículo que justificaba los atentados en los siguientes términos:

Estamos de acuerdo en que los defensores del sistema deben ser atacados personalmente y eliminados, antes de que el propio sistema pueda ser destruido, por tanto apoyamos los asesinatos en lo político y la activa destrucción de la propiedad privada en lo social. ${ }^{51}$

48 The Alarm, Chicago, 21-2-1885.

49 AVRICH: The Haymarket tragedy..., pp. 61-67.

50 CARLSON: Anarchism in Germany..., pp. 277-278, nota 15.

51 NA, Kew, HO 14477 A3385, Metropolitan Police, 9-10-1882, cita de Freiheit, 30-9-1882. 
Los ejemplares de Freiheit eran introducidos clandestinamente en Alemania y Austria, donde el movimiento anarquista se orientó hacia la acción violenta. En agosto de 1883 tuvo lugar en la localidad suiza de St. Gallen una reunión clandestina de anarquistas de lengua alemana, que rechazaron la idea de una gran organización internacional en favor de una estructura descentralizada en pequeños grupos y del empleo de la propaganda por el hecho. Al igual que Cafiero había sostenido dos años antes, los reunidos en St. Gallen creían que esos pequeños grupos serían más difíciles de infiltrar por la policía, pero de hecho entre ellos había dos confidentes pagados por la policía alemana. Estuvieron también en St. Gallen tres anarquistas que en los meses siguientes protagonizarían una campaña de atentados en Alemania y Austria: Hermann Stellmacher, Anton Kammerer y Michael Kumics. Fue Kammerer quien inició los crímenes del grupo, con los asesinatos de un farmacéutico y un soldado en Estrasburgo en octubre de 1883, de un banquero en Stuttgart al mes siguiente, y del jefe de policía de Viena en diciembre, pero el crimen más terrible, el que generó más rechazo, fue el que tuvo lugar en esa misma ciudad en enero de 1884, cuando unos anarquistas, tras haber asesinado a un cambista de moneda para robarle, mataron con un hacha a sus dos hijos menores de edad. Poco después Stellmacher fue arrestado tras haber matado a un policía y en febrero lo fue Kamperer. Ambos fueron condenados a muerte y ahorcados en el verano de $1884 .{ }^{52}$

Esta experiencia de propaganda por el hecho tuvo resultados nefastos para sus promotores. El movimiento anarquista quedó desarticulado en Austria, Suiza dejó de ser un refugio seguro cuando las autoridades comenzaron a expulsar a numerosos militantes y sobre todo la imagen del anarquismo quedó desacreditada en los países de lengua alemana, por su asociación con crímenes tan repugnantes como el asesinato del cambista vienés y sus dos hijos. Los esfuerzos de Most para exaltar como mártires a Stellmacher y Kamperer no tuvieron eco entre los trabajadores.

Además de los citados, se cometieron en Alemania y Austria otros atentados entre 1883 y 1885 , pero se frustró uno que de haber tenido éxito habría tenido una enorme repercusión, el intento de volar con dinamita al emperador y a toda la plana mayor de la realeza y la aristocracia alemanas durante la inauguración de un monumento nacional en Niederwald, junto al Rhin, en septiembre de 1883. Su promotor fue August Reinsdorf, quien años atrás había escrito a Most que la única solución posible para la cuestión social era una segunda "noche de san Bartolomé", en referencia a la matanza de protestantes perpetrada por los católicos en París en el siglo XVI. Reinsdorf consiguió reunir en torno a sí a un grupo de obreros que aceptaron dedicarse a la propaganda por la acción. Una lesión en el tobillo le impidió participar personalmente en el atentado de Niederwald, que fracasó porque una fuerte lluvia inutilizó la mecha de baja calidad con la que dos de sus camaradas debían hacer estallar la dinamita al paso de la comitiva imperial. Reinsdorf y uno los dos autores materiales del frustrado atentado fueron ejecutados en febrero de 1885 y con ello concluyó la historia de la propaganda por el hecho en Alemania. ${ }^{53}$

52 CARLSON: Anarchism in Germany..., pp. 259-272.

53 CARLSON: Anarchism in Germany..., pp. 79 y 283-299. 
Al congreso de Londres habían asistido delegados de catorce grupos franceses, ocho de ellos de París y dos de Lyón. Ninguna publicación anarquista francesa tenía sin embargo por entonces una influencia comparable a la de Freiheit o Le Révolté. ${ }^{54}$ Por otra parte, en Francia el primer ejemplo sonado de propaganda por el hecho no fue obra de ninguno de los grupos anarquistas que comenzaban a proliferar, sino de un joven obrero sin trabajo apellidado Fournier, quien en marzo de 1882, al final de una huelga de tejedores en Roanne, hirió de un tiro a uno de los patronos más intransigentes, un acto que recibió grandes elogios por parte de anarquistas como Émile Gauthier, uno de los más activos propagandistas de la causa, que había participado en congreso de Londres. ${ }^{55}$

Pocos meses después se inició la acción de un grupo secreto, conocido como la Bande Noire (banda negra) y radicado en la región industrial y minera centrada en torno a Le Creusot y Montceau-les-Mines, en el noreste de Francia. En una serie de atentados de carácter anticlerical fueron destruidas varias cruces y luego, en la noche del 15 de agosto de 1882, más de cien personas atacaron una capilla y una escuela de monjas de una pequeña aldea, empleando hachas, dinamita y finalmente el fuego. ${ }^{56}$ En las páginas de Le Révolté, el influyente periódico quincenal anarquista que Kropotkin publicaba en Ginebra, los sucesos que se produjeron en Montceau-les-Mines y otros lugares de Francia se presentaban como el preludio de una revolución que por primera vez no sería controlada por los politicastros burgueses. ${ }^{57}$ Pero lo cierto es que la agitación no se mantuvo durante mucho tiempo. Pronto se produjeron numerosas detenciones y en diciembre de 1882 fueron condenados nueve acusados. Sin embargo, la Bande noire reanudó sus atentados con dinamita en 1883 y 1884, hasta que la policía logró contar con dos confidentes, que permitieron su desarticulación. En mayo de 1885 diez de sus miembros fueron condenados a trabajos forzados. ${ }^{58}$

Entre tanto, el 22 de octubre de 1882 se había producido en Lyón un atentado con dinamita contra el restaurante de un teatro, que causó la muerte de un empleado y que, según Le Révolté, fue percibido por la opinión pública como una venganza anarquista por las detenciones efectuadas en Montceau-les-Mines. Por su implicación en ese atentado fue condenado Antoine Cyvoct, a quien se acusó de haber publicado en el periódico anarquista de Lyón Le Droit Social, del que era editor, un artículo donde se decía que la revolución destruiría ese restaurante burgués, aunque no se pudo demostrar que él mismo hubiera puesto la bomba. Cyvcot había huido a Bruselas, donde se dedicó a hacer experiencias químicas con un amigo, hasta que una bomba le explotó a éste causándole la muerte en febrero de 1883, tras lo cual el propio Cyvcot fue arrestado y finalmente extraditado. Condenado a muerte en diciembre de 1883, se le conmutó la condena y fue finalmente amnistiado en $1898 .{ }^{59}$

En la tensa atmósfera creada por tales acontecimientos se celebró el proceso de Lyón de enero de 1883, con el que las autoridades trataron de decapitar el movimien-

54 AN, París, F7 12504, «Les menées anarchistes», 25-2-1886.

55 MAITRON: Le mouvement anarchiste..., pp. 154-155. AN, París, F7 12504, 25-2-1886.

56 MAITRON: Le mouvement anarchiste..., pp. 155-165.

57 Le Révolté, Ginebra, 28-10-1882.

58 MAITRON: Le mouvement anarchiste..., pp. 165-166.

59 MAITRON: Le mouvement anarchiste..., pp. 166-170. Le Révolté, Ginebra, 21-12-1883. 
to anarquista francés. Hubo cincuenta y dos procesados, entre los que se encontraban los principales militantes de Lyón, el parisino Émile Gauthier, que había participado en el congreso de Londres, y el propio Kropotkin. Éste había sido expulsado de Suiza en agosto de 1881, debido a la propaganda que había realizado en homenaje a los condenados por el asesinato del zar Alejandro II, y fue detenido Francia en diciembre de 1882. De acuerdo con una ley de 1872, se acusó a los procesados de "atentado a la paz pública" por su pertenencia a una "asociación internacional" que tenía el propósito de incitar "a la suspensión del trabajo, a la abolición del derecho de propiedad, de la familia, de la patria y de la religión". En realidad, los grupos franceses no estaban federados a organización alguna de carácter internacional ni nacional, así es que los acusados decían la verdad cuando afirmaron en el proceso que entre los anarquistas de todos los países había una comunidad de opiniones y de aspiraciones, pero no una asociación. Cuarenta y siete de ellos firmaron un documento, que uno leyó en el juicio, en él que expusieron sus principios en los siguientes términos:

Los anarquistas, señores, son unos ciudadanos que, en un siglo en el que por todas partes se proclama la libertad de las opiniones, han creído que era su derecho y su deber encomendarse a la libertad ilimitada. (...) Queremos la libertad y creemos que su existencia es incompatible con la de cualquier tipo de poder, cualquiera que sea su origen y su forma, ya sea elegido o impuesto, monárquico o republicano (...). Los anarquistas se proponen enseñar al pueblo a prescindir del gobierno como ha prescindido de Dios. Aprenderá igualmente a prescindir del propietario. (...) De cada uno según sus facultades, a cada uno según sus necesidades $(\ldots)^{60}$

Kropotkin, Gauthier y otros procesados fueron condenados a cinco años de prisión, mientras que los demás recibieron penas menores ${ }^{61} \mathrm{El}$ anarquismo francés había recibido un duro golpe y la militancia se retrajo. El propio Gauthier, una de las grandes figuras del movimiento, perdió en prisión su fe en la doctrina anarquista y recibió un indulto en $1884 .{ }^{62}$ Kropotkin, en cambio, se mantuvo firme en sus convicciones, pero su condena levantó protestas en ambiente muy lejanos al anarquismo, especialmente en Inglaterra, donde destacados intelectuales firmaron una petición para que fuera liberado en razón de sus contribuciones a la ciencia, petición que Victor Hugo presentó al ministro de Justicia francés. Fue perdonado en enero de 1886 y dos meses después se instaló en Londres, que sería su lugar de residencia durante más de treinta años, sin que volviera a tener problemas con la justicia.

El proceso de Lyón y de Jerez en 1883, la ejecución de Reinsdorf en 1885 y la bomba de Chicago en 1886 pusieron fin a una etapa de acción anarquista directamente vinculada al llamamiento del congreso de Londres. Luego, durante seis años, no hubo atentados significativos, hasta que a partir de 1892 los realizados por Ravachol y sus continuadores en París y los aún más graves de Barcelona dieron inicio a la gran era del terrorismo anarquista. Entre tanto, el gran proyecto de recrear la Asociación Internacional de Trabajadores, que había estado en el origen del congreso de 1881,

60 Gazette des Tribunaux, París, 14-1-1883.

61 Gazette des Tribunaux, París, 20-1-1883.

62 MAITRON: Le mouvement anarchiste..., pp. 173-176. 
había quedado olvidado. En espera de la insurrección revolucionaria que nunca llegaba y habiendo renunciado a la acción política y a la creación de organizaciones obreras de masas, tareas que ocupaban las energías de sus rivales marxistas, algunos anarquistas de los años ochenta y noventa encontraron en los atentados la falsa sensación de haber lanzado un gran desafío al orden burgués.

\section{Bibliografía}

AVILÉS, Juan: "El terrorismo anarquista como propaganda por el hecho: de la formulación teórica a los atentados de París, 1877-1894", Historia y Política, 21, 2009.

AVRICH, Paul: The Haymarket tragedy, Princeton University Press, 1984.

BACH JENSEN, Richard: "Daggers, rifles and dynamite: anarchist terrorism in nineteenth century Europe", Terrorism and Political Violence, 16, 2004.

BERTI, Giampietro: Errico Malatesta e il movimento anarchico italiano e internazionale, 1872-1932, Milano, Franco Angeli, 2003.

CARLSON, Andrew R.: Anarchism in Germany: the early movement, Metuchen, N.J., Scarecrow Press, 1972.

CASTRO ALFÍN, Demetrio: Hambre en Andalucia: antecedentes y circunstancias de la Mano Negra, Ayuntamiento de Córdoba, 1986.

DADÁ, Adriana: L'anarchismo in Italia fra movimento e partito: storia e documenti dell'anarchismo italiano, Florencia, Teti, 1984.

FLEMING, Marie: «Propaganda by the deed: terrorism and anarchist theory in late nineteenth-century Europe», en Y. ALEXANDER y K. A. MYERS (eds.): Terrorism in Europe, Londres, Croom Helm, 1982.

GREEN, James: Death in the Haymarket, Nueva York, Anchor Books, 2006.

GUILLAUME, James: L'Internationale, documents et souvenirs, 1864-1878, 19051910.

LIDA, Clara E.: La mano Negra: anarquismo agrario en Andalucía, Madrid, Zyx, 1973

MAITRON, Jean: Le mouvement anarchiste en France, París, François Maspero, 1975.

NETTLAU, Max: Anarchisten und Sozialrevolutionäre: die historische entwicklung des anarchismus in der jahren 1880-1886, Berlin, Asy-Verlag, 1931.

ROCKER, Rudolf: Johann Most, 1927.

TERMES, Josep: Anarquismo y sindicalismo en España: la Primera Internacional, 1864-1881, Barcelona, Ariel, 1972. 